\title{
Research Article \\ Studies on seed maturation in Butea monosperma (Lam.) Taub. for identification of best collection time
}

\author{
Maitreyee Kundu and Tehsildar Singh
}

\section{SUMMARY}

The purpose of this study is to determine the optimal harvest time for seeds of Butea monosperma as defined by fruit maturation stage. The seeds were harvested at different stages of their development and fruit and seed size, fresh and dry mass, moisture content, germination percentage, tolerance to drying were recorded. Though fresh weight of both fruits and seeds reached maximum at 58 DAA, dry weight of fruits and seeds continued to increase upto 73 DAA till the time of seed dispersal. Onset of germinability (25\%) was observed at 58 DAA before the completion of dry mass accumulation. Full germinability and tolerance to low moisture content were achieved at 73 DAA at the time of seed shedding. At this stage colour of the seed turned brown that can be used as a visual indicator for time of seed collection.

Key Words : Butea monosperma, Seed maturation, Dry weight, Germination, Desiccation tolerance, Maturation indicator

How to cite this article : Kundu, Maitreyee and Singh, Tehsildar (2021). Studies on seed maturation in Butea monosperma (Lam.) Taub. for identification of best collection time. Internat. J. Plant Sci., 16 (1): 19-24, DOI: 10.15740/HAS/IJPS/16.1/19-24, Copyright@ 2021: Hind Agri-Horticultural Society.

Article chronicle : Received : 27.09.2020; Revised : 05.11.2020; Accepted : 04.12.2020

Email : spalliwest@yahoo.co.in 